\title{
Bronquite infecciosa das galinhas: conhecimentos atuais, cepas e vacinas no Brasil
}

\author{
Infectious bronchitis of chickens: current knowledge, strains and vaccines in Brazil
}

\author{
Juliana Figueiredo Pitangui MendonçaI Nelson Rodrigo da Silva Martins ${ }^{\text {II }}$ \\ Leandro Barbiéri de Carvalho ${ }^{\text {III }}$ Marcos Eielson Pinheiro de SáIII, IV \\ Cristiano Barros de Melo ${ }^{\mathrm{IV}^{*}}$
}

\section{- REVISÃO BIBLIOGRÁFICA -}

\section{RESUMO}

A bronquite infecciosa das galinhas (IB) é uma doença viral aguda e altamente contagiosa que provoca grandes perdas econômicas à indústria avícola em todo o mundo. Considerando que surtos têm ocorrido no Brasil com emergência de novas variantes de IBV, desafiando as estratégias de vacinação atuais, este trabalho objetiva revisar os conhecimentos sobre IB e IBV, a sua distribuição, as cepas e as vacinas utilizadas no Brasil.

Palavras-chave: bronquite infecciosa, galinhas, IBV, vírus, coronavírus, ave.

\section{ABSTRACT}

Infectious bronchitis (IB) is an acute, highly contagious disease of chickens, caused by infectious bronchitis virus (IBV), which results in great economic losses to the poultry industry worldwide, despite the routine use of vaccines. Several outbreaks do occur periodically in densely populated poultry regions in Brazil and there are constant emergence of new variants. The aim of this paper is to review the current knowledge about IBV and IB, the distribution, strains and vaccines in Brazil.

Key words: infectious bronchitis, chicken, IBV, virus, coronavirus, fowl.

\section{INTRODUÇÃO}

Bronquite Infecciosa das galinhas (IB) é uma doença viral aguda e altamente contagiosa que provoca grandes perdas econômicas à indústria avícola em todo o mundo, apesar do uso rotineiro e difundido de vacinas vivas e inativadas comercialmente disponíveis (MONTASSIER et al., 2008; LIU et al., 2009).

A doença foi descrita pela primeira vez nos EUA, em 1931, por SCHALK \& HAWN e, dois anos após, BUSHNELL \& BRANDLY notificaram uma doença idêntica, mas diagnosticaram-na como laringotraqueíte infecciosa (LT). Em 1936, BEACH \& SCHALM provaram, por meio de estudos de imunidade cruzada, que o agente da IB era um vírus diferente do vírus da LT e denominaram-no de vírus da bronquite infecciosa (IBV). No início da década de 60, a IB já havia sido notificada em quase todo o mundo (MUNEER et al., 1988).

O objetivo deste trabalho é apresentar os conhecimentos atuais sobre a IB, principalmente a etiologia, a patogenia, os sinais clínicos, a epidemiologia, a imunidade, o diagnóstico, o controle e os aspectos específicos de IBV e IB no Brasil, como distribuição, cepas e vacinas.

\footnotetext{
IPrograma de Pós-graduação em Saúde Animal, Faculdade de Agronomia e Medicina Veterinária (FAV), Universidade de Brasília (UnB), Brasília, DF, Brasil.

IIDepartamento de Medicina Veterinária Preventiva, Escola de Veterinária, Universidade Federal de Minas Gerais (UFMG), Belo Horizonte, MG, Brasil.

IIIMinistério da Agricultura, Pecuária e Abastecimento (MAPA), Brasília, DF, Brasil.

IVPrograma de Pós-graduação em Ciências Animais, FAV, UnB, Brasília, DF, 70910-970; Brasil E-mail: cristianomelo@unb.br.

*Autor para correspondência.
} 
Etiologia

O vírus da IB pertence ao gênero Coronavirus, família Coronaviridae e ordem Nidovirales (MONTASSIER et al., 2008). O gênero é separado em três grupos de acordo com suas características genéticas e antigênicas, sendo o IBV pertencente ao grupo 3 (MCKINLEY et al., 2008). Os patógenos desse grupo são exclusivos de aves, e IBV é uma mistura de mutantes genéticos (JACKWOOD et al., 2003) gerados por mutações pontuais, deleções, inserções e recombinações que ocorrem durante a replicação do RNA viral (LAI \& HOLMES, 2001). As mudanças ativas e constantes da população viral permitem a seleção da subpopulação de IBV melhor adaptada ao hospedeiro, garantindo sobrevivência longa do vírus na célula, no organismo e na população hospedeira, levando as mudanças na patogenicidade e à emergência de novos patógenos virais (DOMINGO et al., 1998).

O genoma do IBV é constituído de RNA de 27,6kDa de fita simples positiva, que codifica quatro proteínas estruturais. A nucleoproteína (N) está associada ao genoma viral para formar o nucleocapsídeo (NC), enquanto as outras proteínas estruturais - projeções superficiais - spikes (S), proteína da membrana (M) e do envelope (E) - estão inseridas no envelope que circunda o nucleocapsídeo. As proteínas M e E são necessárias à formação da partícula viral (MCKINLEY et al., 2008). Aglicoproteína S contém, na subunidade $\mathrm{S} 1$, epítopos heterólogos entre os diferentes sorotipos do vírus que desempenham importante papel na adsorção ao receptor celular e entrada do vírus na célula hospedeira, além de induzirem anticorpos neutralizantes (CAVANAGH, 2007). O genoma também codifica o complexo replicase, que é responsável pelo processo descontínuo de transcrição que leva à geração de um conjunto de seis mRNAs coterminais subgenômicos. Uma região não codificada (untranslated region - UTR) está localizada no final 5'e 3’ do genoma (SAWICKI et al., 2007). O gene da polimerase consiste de duas estruturas de leitura abertas: ORF1a e ORF1b, que participam da transcrição do RNA e processam as proteinases responsáveis pela clivagem da poliproteína em produtos funcionais, sendo o gene da polimerase necessário e suficiente para a replicação e transcrição do genoma. Entretanto, a proteína do NC aumenta consideravelmente a replicação do genoma do coronavírus (SCHELLE et al., 2005), sugerindo que essa proteína possui papel importante na regulação da replicação do coronavírus. A poliproteína 1ab (pp1ab) contém uma proteinase 3C-semelhante (3CLpro) e uma proteinase papaína-semelhante (PLP), que dão origem a 15-16 proteínas não estruturais (nsps). Tais proteínas estão associadas à replicação e transcrição do RNA (CAVANAGH, 2007).

O IBV protótipo é a cepa Massachusetts M41, do sorotipo Massachusetts. O principal sítio determinante da indução de anticorpos neutralizantes contra IBV, que define o sorotipo, reside na subunidade S1 da proteína S (OIE, 2008), e a evolução sorotípica do vírus parece estar relacionada primariamente à sequência dessa subunidade (LIU et al., 2006). As diferenças entre sorotipos de IBV devem-se principalmente às variações na sequência de aminoácidos de duas regiões da subunidade $S_{1}$ do envelope, chamadas regiões hipervariáveis. Diferenças sutis na composição de nucleotídeos do gene correspondente à $\mathrm{S}_{1}$ podem dar origem a novos sorotipos. A capacidade de mutação e recombinação de IBV e a pressão de seleção exercida pelo uso prolongado de vacinas vivas contribuem para o aparecimento de uma grade variedade de sorotipos e subtipos de IBV, sendo os sorotipos Massachusetts 82828, Beaudette 66579 (cepa mutante derivada da cepa Massachusetts), Connecticut e Arkansas os mais conhecidos (DI FABIO \& ROSSINI, 2000).

As mutações são aleatórias e ocorrem no IBV devido ao fato de o vírus possuir RNA como material genético. A ausência de fita dupla pode impedir a reparação de erros durante o processo de replicação. Evidências bioquímicas e estruturais sugeriram que a RNA-replicase e a Transcriptase Reversa dos vírus RNA falham na edição da atividade da exonuclease 3'5', aumentando a predisposição dos vírus RNA a mutações (FRICDBERG et al., 1995) e tornando a população de RNA vírus heterogênea. Organismos infectados ou partes de um mesmo organismo podem conter conjuntos de mutantes distinguíveis, contribuindo para a geração de variantes por recombinação genética, e essa recombinação acontece principalmente em vírus que possuem genoma segmentado, com permutações de genes de um mutante para outro. As mutações também podem conduzir ao surgimento de quasi-espécies, conceito evolutivo para grande grupo de genótipos relacionados que coexistem em ambiente com grande pressão de seleção, provocada pelo uso contínuo de vacinas vivas, em que é esperada uma ou mais mutações em grande parcela das progênies virais. Quasis-espécie constitui grande reservatório de

Ciência Rural, v.39, n.8, nov, 2009. 
variantes que possuem fenótipos potencialmente adaptáveis a mudanças ambientais diversas, que garante a permanência de determinados genótipos na população viral (DOMINGO et al., 1996).

\section{Patogenia e sinais clínicos}

IBV afeta primariamente o trato respiratório (TR) das aves, sendo esse o principal sítio de replicação viral. O vírus causa lesões no trato respiratório, reprodutivo, urinário e digestivo, tanto em poedeiras, como em reprodutoras e aves de corte (CAVANAGH, 2003). É primariamente epiteliotrópico, replicando-se nas células epiteliais, nas células secretoras de muco e nas células epiteliais dos pulmões e dos sacos aéreos. Durante a replicação, IBV causa estase dos cílios traqueais, tanto in vivo, quanto in vitro, e esse parâmetro tem sido usado para inferir sobre a severidade da infecção no TR (DHINAKAR \& JONES, 1997). A replicação do vírus nos tecidos do TR causa sinais característicos, mas não patognomônicos, como dificuldades para respirar, tosse e descarga nasal.

Em poedeiras, IBV pode causar severo declínio na produção e, posteriormente, diminuição do tamanho, da qualidade interna e da casca do ovo (MUNEER et al., 1988; DHINAKAR \& JONES, 1997). Esses efeitos podem ser acompanhados por sinais respiratórios moderados ou ausentes. A severidade no declínio da produção de ovos varia de acordo com o período de postura, a virulência do vírus envolvido e outros fatores não específicos (CAVANAGH, 2003). A produção pode voltar a aumentar após duas ou três semanas, mas atinge apenas níveis subótimos. A infecção de fêmeas com menos de duas semanas de idade pode causar dano permanente ao desenvolvimento do trato reprodutivo (DHINAKAR \& JONES, 1997).

Muitas cepas de IBV já foram isoladas a partir de swabs cloacais, fezes e tonsilas cecais, além do proventrículo, duodeno e jejuno, mas a multiplicação do agente nesses tecidos ainda não foi confirmada, presumindo-se que ocorra nas células epiteliais. Apesar disso, a multiplicação de IBV no íleo e reto já foi descrita, mas ainda se desconhece se IBV se multiplica no esôfago ou se é deglutido após ser expelido da traqueia. Algumas cepas possuem capacidade de sobreviver, tanto na presença de baixo $\mathrm{pH}$, quanto na presença de enzimas digestivas e sais biliares, característica relevante para a replicação entérica. As cepas enterotrópicas de IBV podem causar diarreia nas aves infectadas (DHINAKAR \& JONES, 1996). A replicação do agente nos rins foi demonstrada nos túbulos proximais, distais e coletores (CHEN et al., 1996). Formação e deposição de imunocomplexos nos rins são observadas em infecções causadas por algumas cepas causadoras de doença renal severa, acompanhada de nefrite, nefrose, gota e uremia (WINTERFIELD \& ALBASSAM, 1984). A deposição de imunocomplexos pode ser observada também nas paredes capilares dos músculos peitorais das aves, causando, nesses casos, miopatia bilateral (DHINAKAR \& JONES, 1996). IBV já foi isolado da glândula Harderiana, da bursa de Fabricius e de outros tecidos, como fígado e baço. ZHU et al. (2007) isolaram grande quantidade de IBV de pâncreas de aves contaminadas, sugerindo que o vírus tenha tropismo também para esse órgão.

O período de incubação da IB pode ser de até 50 dias, e as infecções podem ocorrer associadas a infecções respiratórias bacterianas e virais, o que constitui fator importante na patogenia da IB (CAVANAGH, 2003). Vários patógenos respiratórios, como Mycoplasma gallisepticum, Escherichia coli, Haemophilus paragallinarum, vírus da doença de Newcastle e vírus da doença de Gumboro, podem interagir sinergicamente com IBV ou com vírus vacinais, aumentando a severidade e duração da doença (MATTHIJS et al., 2009).

Geralmente a IB é uma doença respiratória aguda, havendo excreção viral persistente, e os rins como sítios mais prováveis de persistência viral. A ocorrência da persistência também pode estar relacionada à idade das aves, e animais infectados na segunda semana não apresentam reexcreção viral, ao contrário daqueles infectados no primeiro dia de vida, sendo a reexcreção não acompanhada por sintomatologia clínica (DHINAKAR \& JONES, 1997).

Imunidade

A resposta imune humoral contra IBV foi estudada em linhagens sensíveis e resistentes. As imunoglobulinas IgM e IgG do soro e IgA na mucosa, específicas para IBV (ELISA), foram avaliadas até 22 dias pós-infecção com a cepa M41. Títulos de IgA para IBV mais altos, mais precoces e mais duradouros foram detectados na lágrima e saliva da linhagem mais resistente Os testes clássicos, menos sensíveis, de soroneutralização e inibição da hemaglutinação, não detectaram diferenças. Existem atualmente poucos estudos sobre os anticorpos contra IBV na narina e traqueia (CAVANAGH, 2003).

MARTINS et al. (1991) estudaram as respostas de IgM e IgG específicas contra IBV após as 
vacinações com vacinas vivas (duas doses, via ocular) e vacina inativada oleosa, aplicada na 17ª semana. As imunoglobulinas foram purificadas por cromatografia de afinidade e de coluna e avaliadas quanto à especificidade e confirmação de classe em ELISA. Anticorpos IgM para IBV podem ser detectados entre seis e nove dias após a aplicação da última vacina (oleosa) e quatro a 20 dias após a aplicação da vacina viva. A proteção da atividade ciliar traqueal contra o desafio com M41 foi demonstrada após a aplicação de vacina viva ocular ou intramuscular, mas não em aves vacinadas apenas com a vacina inativada oleosa. IgM e IgG purificadas do soro aos nove dias após a vacinação viva foram capazes de promover atividade de inibição da hemaglutinação.

Em galinhas, a resposta das células Tcitotóxicas (CTL) à infecção pelo IBV está correlacionada com um declínio inicial na infecção e nos sinais clínicos. A atividade da CTL é principalmente restrita ao complexo de histocompatibilidade e à lise mediada por CD8+ e CD4-. O interferon tipo I em galinhas reduziu a replicação de IBV nas culturas de células renais de pintos, nas culturas de traqueia, e a aplicação oral ou intravenosa desse interferon retarda o aparecimento da doença e reduz sua severidade. Entretanto, estudos são necessários para elucidar as respostas imunes à infecção por IBV (CAVANAGH, 2007).

\section{Lesões macroscópicas e microscópicas}

No trato respiratório, há perda de cílios e descamação das células epiteliais e das células secretoras de muco um a dois dias após a infecção por IBV, com infiltrado de heterófilos e linfócitos na lâmina própria (CHOUSALKAR et al., 2009). Heterófilos podem ser vistos entre as células epiteliais ciliadas e ocasionalmente no lúmen da traqueia. Durante o estágio hiperplásico, células epiteliais neoformadas são observadas e geralmente não possuem cílios. De quatro a seis dias pós-infecção, o processo reparativo é iniciado, com completa recuperação após 10 a 20 dias (CHEN et al., 1996). Nos sacos aéreos afetados, podem ser observados descamação das células epiteliais, edema e exsudato fibrinoso, podendo haver opacidade destes e exsudato caseoso amarelado como conteúdo (DHINAKAR \& JONES, 1997). Em coinfecções com $\boldsymbol{E}$. coli, pode haver pneumonia além da aerosaculite (DWARS et al., 2009). Há ocorrência de estase dos cílios traqueais e algumas áreas de pneumonia podem ser observadas (CHOUSALKAR et al., 2009). No sistema urinário, são observados rins flácidos e pálidos, túbulos e ureteres distendidos com uratos, aumento do peso relativo renal e da assimetria dos rins, além de nefrite intersticial ductotubular. Há degeneração granular, vacuolização e descamação do epitélio tubular, com infiltrado de heterófilos no interstício durante a fase aguda da doença (CHEN et al., 1996). Edema e palidez dos músculos peitorais profundos e hemorragia das fáscias com deposição de edema gelatinoso sobre a superfície destas podem ocorrer nos casos de miopatia peitoral (DHINAKAR \& JONES, 1997).

\section{Diagnóstico}

O diagnóstico de IB requer testes laboratoriais, e o isolamento e a identificação viral são preferíveis. A confirmação do diagnóstico é baseada no isolamento viral, sempre em conjunto com a sorologia (DI FABIO \& ROSSINI, 2000).

Para o diagnóstico virológico, devem ser coletadas amostras da mucosa traqueal e dos pulmões uma semana após a infecção, para a forma respiratória clássica. Para as outras formas de IB, rins, ovidutos, tonsilas cecais do trato intestinal ou tecidos do proventrículo são fontes melhores de vírus, dependendo da patogenia da doença (OIE, 2008).

Para o isolamento e a identificação de IBV, inocula-se macerado de órgãos em cavidade alantoide de ovos Specific Pathogens Free (SPF), com idade entre nove e 11 dias de incubação. Procede-se ao exame do embrião na procura de alterações morfológicas neste, como nanismo, enrolamento, depósito de urato nos mesonefrons e mortalidade embrionária. As técnicas de reação da cadeia de polimerase transcrição-reversa (RT-PCR) são comumente utilizadas para identificação genotípica dos isolados (DI FABIO \& ROSSINI, 2000).

Cultivos de anéis de traqueia foram usados para estudos de cepas de IBV e da resposta imune em galinhas experimentalmente e naturalmente infectadas (EPIPHANIO et al., 2002). O estudo em cultivos de anéis de embriões SPF é o método laboratorial que melhor se aproxima das condições in vivo, embora seja técnica trabalhosa e não oferecida pelos laboratórios em rotina. Testes complementares incluem microscopia eletrônica, uso de anticorpos monoclonais e testes imunohistoquímicos (DI FABIO et al., 2000).

No diagnóstico sorológico, a inibição da hemaglutinação (IH) é uma prova sorológica qualitativa utilizada tanto para identificação sorológica como no sorodiagnóstico do vírus. A identificação sorológica é 
feita por meio da IH de uma amostra viral por um soropadrão. O sorodiagnóstico é a deteç̧ão, no soro do animal, de anticorpo que inibe a hemaglutinação por um vírus específico (DI FABIO et al., 2000). Na forma respiratória clássica, anticorpos começam a aparecer no soro dos animais infectados uma semana após a infecção (OIE, 2008).

Para realizar o teste de IH, é necessário tratamento prévio do vírus com a enzima fosfolipase tipo C, para exposição das hemoaglutininas (DI FABIO \& ROSSINI, 2000), já que IBV não é naturalmente hemaglutinante. Entretanto, devido às múltiplas infecções e vacinações, o soro das aves contém anticorpos que apresentam reações cruzadas, e o resultado do teste de IH não pode ser utilizado com alto grau de confiança, além de ser laborioso e de difícil padronização (DI FABIO \& ROSSINI, 2000; OIE, 2008).

O ELISA é utilizado para monitoramento sorológico da resposta vacinal e para o monitoramento dos desafios de campo. Soro-neutralização viral ou imunofluorescência, além de testes imunização-desafio, também podem ser utilizados (DI FABIO et al., 2000; OIE, 2008). O uso extensivo das vacinas pode complicar o diagnóstico sorológico, já que anticorpos vacinais e contra desafios de campo não podem ser distinguidos daqueles produzidos durante a infecção (OIE, 2008).

Controle

O controle da IB deve ser baseado principalmente na aplicação de medidas de biosseguridade e rigoroso controle sanitário dos plantéis. Vacinas vivas atenuadas e vacinas inativadas em emulsão oleosa são importantes (CAVANAGH, 2007), especialmente para a proteção de poedeiras e reprodutores. As vacinas vivas atenuadas conferem melhor imunidade local no trato respiratório. Entretanto, há o risco de patogenicidade residual, reversão de virulência e persistência (BIJLENGA et al., 2004; MCKINLEY et al., 2008). Dentre as vacinas atenuadas, citam-se a H52 e a H120, derivadas da amostra nefrotóxica Holland (H). A H120 é possivelmente a mais usada globalmente devido à sua capacidade de promover proteção cruzada contra IBVs de diferentes sorotipos (BIJLENGA et al., 2004). O uso da H52 tem declinado devido ao surgimento de vacinas inativadas altamente eficazes e seguras (BIJLENGA et al., 2004). Em regiões avícolas densamente povoadas e sem possibilidade de vazio sanitário, há o risco do uso inadequado das vacinas vivas, com oportunidade de escape de vírus entre lotes e entre granjas próximas, o que torna esse tipo de vacinação uma prática de risco, além do seu alto custo, especialmente em frangos de corte. Entretanto, em poedeiras, a relação custobenefício poderá ser favorável, além do menor risco de escape de vírus virulento na adoção da vacinação nesse tipo de plantel.

As vacinas inativadas estão disponíveis no mercado brasileiro exclusivamente com IBV (algumas com mais de um sorotipo), ou associadas a vacinas contra a doença de Newcastle, síndrome da queda da postura e coriza infecciosa. Devido à variabilidade antigênica das cepas de IBV encontradas no país, sugerem-se programas de vacinação que utilizem mais de um sorotipo vacinal (DI FABIO et al., 2000).

Estudos apontaram novas alternativas de vacinação com vacina in ovo e o uso de genética reversa para o desenvolvimento de clones não infecciosos de IBV (CAVANAGH, 2007). O uso da genética reversa para modificação do gene da proteína S mostrou a possibilidade do desenvolvimento de vacinas para definir os papéis das proteínas virais na patogenicidade de IBV (HODGSON et al., 2006).

A vacinação in ovo tem sido utilizada apenas contra a Doença de Marek, já que tal método de vacinação contra IBV afetaria negativamente a eclosão dos ovos (BIJLENGA et al., 2004; CAVANAGH, 2007). Entretanto, estudos que utilizaram um clone de IBV na vacinação in ovo constataram que esta não mostra virulência quando administrada em embriões de 18 dias, não afetando a eclosão (CAVANAGH, 2007).

\section{Epidemiologia}

A IB está distribuída por quase todo o globo, exceto na Albânia, na Geórgia, na Groenlândia, na Letônia, na Mongólia, em St. Kitts e Nevis, em São Vicente e Granadinas, no Tajiquistão e em Trinidad e Tobago (OIE, 2008). As diferentes cepas do vírus têm tropismo variado e amplo para os tecidos, ocasionando manifestações clínicas variadas (DHINAKAR \& JONES, 1997).

Todas as idades são susceptíveis a infecções por IBV. Entretanto, os sinais clínicos são mais severos em aves jovens. Linhagens resistentes e sensíveis são igualmente susceptíveis à infecção inicial por IBV; no entanto, a recuperação é mais rápida nas primeiras. IBV pode ser transmitido por contato direto ou pelo exsudato bronquial e já foi isolado do sêmen e dos ovos de aves infectadas (DHINAKAR \& JONES, 1997).

A Bronquite Infecciosa no Brasil

Ocorrência

Há evidências de que a doença ocorra em todo o país, e os últimos surtos registrados foram no 
ano de 2007. Quatro deles ocorreram no Estado da Bahia, um no Estado de Pernambuco e um no Estado de Santa Catarina (OIE, 2008). IBV também já foi isolado em São Paulo, no Paraná, no Rio de Janeiro, em Rondônia (DI FABIO et al., 2000), em Minas Gerais (ABREU et al., 2006) e no Distrito Federal (OIE, 2008).

\section{Genótipos e tipos antigênicos brasileiros}

A maioria dos isolados brasileiros, até 1989, foram classificados como sendo do sorotipo Massachusetts-M. Entretanto, das 16 amostras de IBV isoladas por DI FABIO et al. (2000), apenas um sorotipo foi classificado como pertencente ao sorotipo M. Os resultados desse estudo também mostraram que todos os isolados descritos eram antigenicamente diferentes do sorotipo Arkansas. Além disso, eram também diferentes não só entre si, como também daqueles sorotipos descritos em outros países, tendo sido isolados pelo menos cinco tipos antigênicos diferentes que coexistem no sudeste brasileiro.

A predição da composição de aminoácidos (aa) de 15 isolados de IBV obtidos de surtos em frangos de corte e poedeiras em Minas Gerais, realizada por ABREU et al. (2006), indicou variação de 45 (entre as cepas G e 208) até 99\% (cepas PM1 e PM2). Quando comparadas as cepas estudadas àquelas de outros autores, a identidade de aminoácidos foi de 42 (Q3/88 and G) até 97\% (D41 and PM1), indicando grande diversidade genética do vírus.

Diferentes genótipos de IBV foram demonstrados nos plantéis brasileiros por VILLARREAL et al. (2007a), que examinaram a relação entre estes e os sorotipos vacinais utilizados na rotina de vacinação. As análises filogenéticas mostraram que os sorotipos brasileiros apresentavam-se segregados em um grupo exclusivo, próximo ao sorotipo D274, mas filogeneticamente distante do sorotipo Massachusetts, concluindo que a presença de cepas variantes de IBV nos plantéis brasileiros pode ser a razão para o insucesso no controle do vírus no Brasil. Em outro estudo, observou-se a presença de genótipo relacionado ao europeu D274, não descrito previamente em nosso território (VILLARREAL et al., 2007b).

Cinco genótipos diferentes do vírus no Brasil foram descritos por MONTASSIER et al. (2008): M, A, B, C e D (Tabela 1 e Figura 1), confirmando a grande variabilidade genética no pool de IBV no campo, já sugerida por outros autores (DIFABIO et al., 2000; ABREU et al., 2006; VILLARREAL et al., 2007a,b). Entretanto, os estudos sobre a distribuição dos
Tabela 1 - Perfis genéticos de IBV identificados no Sudeste e Sul do Brasil.

\begin{tabular}{ll}
\hline Genótipo & Local do isolamento \\
\hline A & Sudeste \\
B & Sudeste \\
C & Sudeste \\
D & Sul \\
Massachusetts & Sudeste e Sul \\
\hline
\end{tabular}

Adaptada de MONTASSIER et al. (2008).

sorotipos de IBV no Brasil ainda são escassos, gerando dificuldades em se obter uma descrição filogeográfica mais completa e precisa.

\section{Vacinação no Brasil}

As vacinas inativadas estão disponíveis no mercado brasileiro, exclusivamente com IBV (algumas com mais de um sorotipo), ou associadas a vacinas contra a doença de Newcastle, síndrome da queda da postura e coriza infecciosa, e a vacina atenuada H120 tem sido amplamente utilizada no Brasil desde 1979. Resultados parciais de testes de proteção confirmaram que a vacina H120 confere alta proteção contra os IBVs do genótipo M (PEREIRA et al., 2006).

A relação genética entre os isolados brasileiros e as cepas estrangeiras, especialmente aquelas utilizadas na produção de vacinas, ainda é escassamente conhecida, e investigações adicionais são necessárias para melhor caracterizar as mudanças causadas por mutações e/ou recombinações na proteína S1 desses isolados (MONTASSIER et al., 2008) e o grau de proteção dessas vacinas contra infecções causadas por cepas brasileiras de IBV.

\section{CONCLUSÕES}

A IB é uma doença endêmica no Brasil, permanecendo como problema econômico importante para a avicultura, apesar das tentativas de controle por vacinação. Os surtos no país têm ocorrido com frequência e com a emergência de novas variantes do vírus. As vacinas atenuadas devem ser usadas com cautela e, quando necessária a aplicação, deve-se assegurar a adoção de estratégias de aplicação que reduzam a emergência de variantes por conta de reversão de virulência, com a unificação do manejo que permita um cronograma de vacinação regional simultâneo. A melhoria na biosseguridade e a uniformização de plantéis e de manejo são práticas essenciais que podem trazer grandes vantagens no controle da IB. 


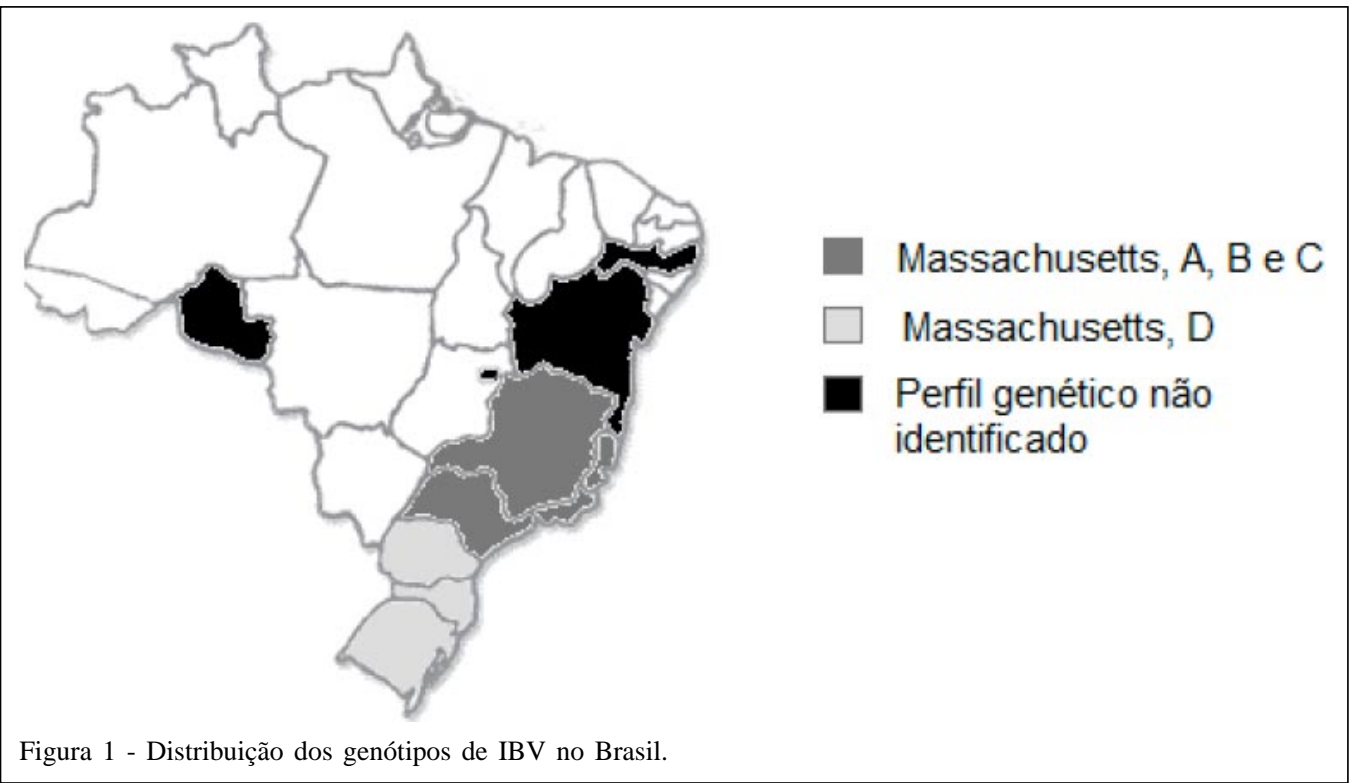

\section{REFERÊNCIAS}

ABREU, J.T. et al. Molecular analysis of brazilian infectious bronchitis field isolates by reverse transcription-polymerase chain reaction, restriction fragment length polymorphism, and partial sequencing of the N Gene. Avian Diseases, v.50, n.4, p.494-501, 2006. Disponível em: <http://www.bioone.org/doi/ pdf/10.1637/7525-030706R.1?cookieSet=1>. Acesso em: 10 jul. 2009. doi: 10.1637/7525-030706R.1.

BIJLENGA, G. et al. Development and use of the $\mathrm{H}$ strain of avian infectious bronchitis virus from the Netherlands as a vaccine: a review. Avian Pathology, v.33, n.6, p. 550-557, 2004. Disponível em: <http://www.ncbi.nlm.nih.gov/pubmed/15763721>. Acesso em: 10 jul. 2009. doi: 10.1080/03079450400013154.

CAVANAGH, D. Severe acute respiratory syndrome vaccine development: experiences of vaccination against avian infectious bronchitis coronavirus. Avian Pathology, v.32, n.6, p.567582, 2003. Disponível em: <http://www.ncbi.nlm.nih.gov/pubmed/ 14676007>. Acesso em: 10 jul. 2009. doi: 10.1080/ 03079450310001621198.

CAVANAGH, D. Coronavirus avian infectious bronchitis virus. Veterinary Research, v.38, p.281-297, 2007. Disponível em: <http://www.vetres.org/articles/vetres/pdf/ 2007/02/ v06178.pdf $>$. Acesso em 10 jul. 2009. doi: 10.1051/ vetres:2006055

CHEN, B.Y. et al. Histopathology and immunochemistry of renal lesions due to infectious bronchitis virus in chickens. Avian Pathology, v.25, p.269-283, 1996. Disponível em: <http://pdfserve.informaworld.com/795293784667205.pdf>. Acesso em: 10 jul. 2009. doi: 10.1080/03079459708419238.

CHOUSALKAR, K.K. et al. Effects of infectious bronchitis virus vaccine on the oviduct of hens. Vaccine 2009 (press). Disponível em: <http://www.sciencedirect.com/ science? ob=ArticleURL\&_udi=B6TD4-4VG5DHP 2\&_user $=10 \&$ \&doc $=1 \&$ _fmt $=$ \&_orig $=$ search\&_sort $=$ d\&_docancho $\mathrm{r}=\&$ view $=$ c\&_acct $=\mathrm{C} 000050221$ \&_version $=1$ \&_urlVersion=0\&_userid $=10$ \&md5=e86863086dadfc6a882e67af351b69a5>. Acesso em: 10 jul. 2009. doi: 10.1016/j.vaccine.2009.01.012.

DHINAKAR, R.G.; JONES, R.C. Immunopathogenesis of infection in SPF chicks and commercial broilers of a variant infectious bronchitis virus of economic importance. Avian Pathology, v.25, p.481-501, 1996. Disponível em: <http:// pdfserve.informaworld.com/293080784675777.pdf>. Acesso em 12 jul. 2009. doi: 10.1080/03079459608419157.

DHINAKAR, R.G.; JONES, R.C. Infectious bronchitis virus: immunopathogenesis of infection in the chicken. Avian Pathology, v.26, p.677-706, 1997. Disponível em: <http:// pdfserve.informaworld.com/168042_784660112.pdf > Acesso em 12 jul. 2009. doi: 10.1080/03079459708419246.

DI FABIO, J. et al. Characterization of infectious bronchitis viruses isolated from outbreaks of disease in commercial flocks in Brazil. Avian Diseases, v.44, p.582-589, 2000. Disponível em: <http://www.jstor.org/stable/1593097>. Acesso em 12 jul. 2009. doi: 10.1080/03079459708419246.

DI FABIO, J.; ROSSINI, L.I. Bronquite infecciosa das galinhas, p.283-300. In: BERCHIERI JÚNIOR, A.; MACARI, M. Doenças das aves. Campinas: Facta, 2000. p.293-300.

DOMINGO, E. et al. Basic concepts in RNA virus evolution. FASEB Journal, v.10, p. 859-864, 1996. Disponível em: <http:/ /www.fasebj.org/cgi/reprint/10/8/859>. Acesso 12 jul. 2009.

DOMINGO, E. et al. Quasispecies structure and persistence of RNA viruses. Emerging Infectious Diseases, v.4, n.4, p.521527, 1998. Disponível em: <http://www.cdc.gov/ncidod/eid/ vol4no4/domingo.htm>. Acesso em: 17 jul. 2009.

DWARS, R.M. et al. Progression of lesions in the respiratory tract of broilers after single infection with Escherichia coli compared to superinfection with $\boldsymbol{E}$. coli after infection with infectious bronchitis virus. Veterinary Immunology and Immunopathology, v.127, n.1-2, p.65-76. 2009. Disponível em: <http://www.sciencedirect.com/ 
science? _ob = A r t i c le URL \&_udi=B 6 T D $5-4$ TK929N1\&_user $=10 \& \_r d o c=1 \& \_f m t=\&$ orig $=$ search\&_sort $=$ d\&_d oc an chor $=\&$ view $=$ c $\&$ _searchStrId $=955072827 \&$ \& rer unOrigin $=$ google $\&$ _acct $=\mathrm{C} 000050221 \&$ _version $=1 \&$ \&urlV ersion=0\&_userid=10\&md5=50ad8ee3d58d828bf08c65cf3761f6ac $>$. Acesso em: 12 jul. 2009. doi: 10.016/j.vetimm.2008.09.019.

EPIPHANIO, E.O.B. et al. Resultados preliminares da utilização de cultivos de anéis de traquéia para o estudo de estirpes brasileiras do vírus da bronquite infecciosa das galinhas. Arquivo Brasileiro de Medicina Veterinária e Zootecnia, v.54, p.212-216, 2002. Disponível em: <http://www.scielo.br/ s cielo.ph p ? script = sci_art text \& pid=S 0102 $09352002000200013 \&$ tlng $=$ en $\&$ lng $=$ en $\& n r m=i s o>$. Acesso em: 15 jul. 2009. doi:10.1590/S0102-09352002000200013.

FRICDBERG, E.C. et al. DNA repair and mutagenesis. Washington. D.C.: American Society for Microbiology, 1995. 1118p.

HODGSON, T. et al. Neither the RNA nor the proteins of open reading frames $3 \mathrm{a}$ and $\mathrm{Bb}$ of the coronavirus infectious bronchitis virus are essential for replication. Journal of Virology, v.80, p.296-305, 2006. Disponível em: <http://jvi.asm.org/cgi/ content/full/80/1/296>. Acesso em: 17 jul. 2009. doi:10.1128/ JVI.80.1.296-305.2006.

JACKWOOD, M.W. et al. Detection of infectious bronchitis virus by real-time reverse transcriptase-polymerase chain reaction and identification of a quasispecies in the Beaudette strain. Avian Diseases, v.47, n.3, p.718-724, 2003. Disponível em: <http://www.bioone.org/doi/full/10.1637/6075. Acesso em: 17 jul. 2009. doi: 10.1637/6075>.

LAI, M.M.C.; HOLMES, K.V. Coronaviridae: the viruses and their replication. In: KNIPE, D.M. et al. Fields virology. 4.ed. Philadelphia, PA: Lippincott Williams \& Wilkins, 2001. p.1163-1185.

LIU, S.W. et al. Genetic diversity of avian infectious bronchitis coronavirus strains isolated in China between 1995 and 2004. Archives of Virology, v.151, n.6, p.1133-1148, 2006. Disponível em: <https://commerce.metapress.com/content/ 7 h 866562 ku 16 g 425 / resource-s e c ured/ ? t a r g e t $=$ f ull text.pdf \& sid $=0$ oj 3 ld 31 h z 1 zx 5 553bqwowyc\&sh=www.springerlink.com10.1007/s00705-0050695-6>. Acesso em: 17 jul. 2009.

LIU, S. et al. Evaluation of the protection conferred by commercial vaccines and attenuated heterologous isolates in China against the CK/CH/LDL/97I strain of infectious bronchitis coronavirus. Veterinary Journal, v.179, n.1, p.130-136, 2009. Disponível em: <http://www.sciencedirect.com/ science?_ob=ArticleURL\&_udi=B6WXN-4R1NNNK$3 \& \_$user $=108 \_$rdoc $=1 \& \_$fmt $=$\&_orig $=$search\&_sort $=\mathrm{d} \& \_$docanchor $=\&$ view $=$ c\&_searchStrId $=955095987 \&$ \&erunOrigin $=$ google \&_ac $\mathrm{ct}=\mathrm{C} 000050221 \&$ \& version $=1$ \&_url Version $=$ 0\&_userid=10\&md5=e7ef21e273140574217910a14f935975>. Acesso em: 17 jul. 2009. doi: 10.1016/j.tvjl.2007.08.018.

MARTINS, N.R.S. et al. IgM responses in chicken serum to live and inactivated infectious bronchitis virus vaccines. Avian Diseases, v.35, p.470-475, 1991.

MATTHIJS, M.G.R. et al. Course of infection and immune responses in the respiratory tract of IBV infected broilers after superinfection with $\boldsymbol{E}$. coli. Veterinary Immunology and Immunopathology, v.127, n.1-2, p.77-84, 2009. Disponível em: <http://www.ncbi.nlm.nih.gov/pubmed/18976820>. Acesso em: 17 jul. 2009. doi: 10.016/j.vetimm.2008.09.019.

MCKINLEY, E.T. et al. Avian coronavirus infectious bronchitis attenuated live vaccines undergo selection of subpopulations and mutations following vaccination. Vaccine, v.26, p.12741284, 2008. Disponível em: <http://www.sciencedirect.com/ s c i ence ? _ o b = A r t i c l e UR L \&_u d i = B 6 T D 4 4RM88279\&_user=10\&_rdoc $=1 \&$ fmt $=\&$ \&orig=search \&_sort $=\mathrm{d} \&$ _docanchor $=\&$ view $=$ c \&_searchStrId $=955099419 \&$ \& e runOrigin=google \&_a c c t = C 000050221 \&_ver sion=1\&_unlVerision=0\&_userid=10\&md5=ae0a7379d4bc2ed780451c966dd9ba67> Acesso em: 17 jul. 2009. doi: 10.1016/j.vaccine.2008.01.006.

MONTASSIER, M.F.S. et al. Genetic grouping of avian infectious bronchitis virus isolated in Brazil, based on RT-PCR/ RFLP analysis of the $\mathrm{S} 1$ gene. Pesquisa Veterinária Brasileira v.28, n.3, p.190-194, 2008. Disponível em: <http:/ /www.scielo.br/pdf/pvb/v28n3/11.pdf>. Acesso em: 17 jul. 2009.

MUNEER, M.A et al. Efficacy of infectious bronchitis virus vaccines against heterologous challenge. Research in Veterinary Science, v.45, p.22-27, 1988. Disponível em: https://www.researchgate.net/publication/20304114. Acesso em: 17 jul. 2009.

OIE - ORGANIZAÇÃO MUNDIAL DE SAÚDE ANIMAL. Disponível em: <http://www.oie.int>. Acesso em 27 nov. 2008.

PEREIRA, N.A. et al. Uma nova cepa brasileira do vírus da bronquite infecciosa causadora de lesões gonadais e aproteção cruzada induzida pela vacina comercial atenuada. Arquivos do Instituto Biológico, v.68, n.2, p.250-254, 2006. Disponível em: <http://www.scielo.br/pdf/pvb/v28n3/11.pdf>. Acesso em 17 jul. 2009.

SAWICKI, S.G. et al. A contemporary view of coronavirus transcription. Journal of Virology, v.81, n.1, p.20-29, 2007. Disponível em: <http://jvi.asm.org/cgi/content/full/81/1/20>. Acesso em 17jul2009. doi:10.1128/JVI.01358-06.

SCHELLE, B. et al. Selective replication of coronavirus genomes that express nucleocapsid protein. Journal of Virology, v.79, n.11, p.6620-6630, 2005. Disponível em: $<$ http://jvi.asm.org/cgi/content/full/79/11/6620>. Acesso em: 17 jul. 2009. doi:10.1128/JVI.79.11.6620-6630.2005.

VILLARREAL, L.Y. et al. Orchitis in roosters with reduced fertility associated with avian infectious bronchitis virus and avian metapneumovirus infections. Avian Diseases, v.51, n.4, p.900-904, 2007a. Disponível em: <http://cat.inist.fr/ ?aModele $=$ afficheN\&cpsidt $=19951504>$. Acesso em: 15 jul. 2009.

VILLARREAL, L.Y. et al. Molecular characterization of infectious bronchitis virus strains isolated from the enteric contents of brazilian laying hens and broilers. Avian Diseases, v.51, n.4, p.974-978, 2007b. Disponível em: <http:// www.bioone.org/doi/abs/10.1637/7983-041307.1>. Acesso em: 15 jul. 2009. doi: 10.1637/7983-041307.1.

WINTERFIELD, R.W.; ALBASSAM, M.A. Nephropathogenicity of infectious bronchitis virus. Poultry Science, v.63, p.23582363, 1984.

ZHU, J. G. et al. Analysis of similarity of the S1 gene in infectious bronchitis virus (IBV) isolates in Shanghai, China. Archivos de Medicina Veterinaria, v.39, n.3, p.223-228, 2007. Disponível em: <http://www.scielo.cl/pdf/amv/v39n3/art05.pdf.>. Acesso em: 15 jul. 2009. 